\title{
Short introduction to the K2S1 project
}

\author{
Makio C. Honda ${ }^{1}$
}

Published online: 4 May 2016

(c) The Oceanographic Society of Japan and Springer Japan 2016

The ocean controls the global carbon cycle, containing about 50 times as much $\mathrm{CO}_{2}$ as the atmosphere and absorbing about one-third of anthropogenic annual $\mathrm{CO}_{2}$ emissions. The "biological pump" is one of the important mechanisms by which atmospheric $\mathrm{CO}_{2}$ is taken up by the ocean and transported to the ocean's interior. Recent increases of atmospheric $\mathrm{CO}_{2}$ and associated global warming have caused warming, freshening, stratification, deoxygenation (hypoxia), and acidification of the ocean. There is now great concern that these changes of the ocean environment ("multi-stressors") will affect the biological pump and its ability to mitigate the increases of atmospheric $\mathrm{CO}_{2}$ in the future. Numerical simulations have been used to predict possible future changes in the components of the biological pump (predominant phytoplankton species, primary production, calcification, settling of particles, etc.) caused by these multi-stressors. Previous studies pointed out that the magnitude and effect of multi-stressors on marine biogeochemistry will differ from one locality to another. Since the western North Pacific is one of the strong biological pump regions, it is thus of great concern to characterize the current status of the ocean, to identify limiting factors from a biogeochemical standpoint, and to predict possible changes of the biological pump and biogeochemical cycles caused by changes. Although comprehensive time-series biogeochemical observations were previously conducted in the Western Pacific Subarctic gyre (WSG; see special issue of Deep-Sea Research II vol. 49, no. 24-25), insufficient

Makio C. Honda

hondam@jamstec.go.jp

1 Department of Environmental Geochemical Cycle Research, Japan Agency for Marine-Earth Science and Technology, 2-15, Natsushima, Yokosuka 237-0061, Kanagawa, Japan attention was given to the role of zooplankton and bacteria in the carbon cycle and to the factors that limit primary production. In addition, the location of the time-series station (KNOT: $44^{\circ} \mathrm{N}, 155^{\circ} \mathrm{E}$ ) was not always representative of the WSG: KNOT was located at the southwest edge of the WSG, and subtropical water sometimes invaded that station. More importantly, a comparative, comprehensive biogeochemical study of the Western Pacific Subtropical region was not conducted.

To facilitate predictions about changes of material cycles associated with biological activity, a comparative study to collect essential baseline data about the WSG ecosystem, its physics, and the biological pump was conducted at time-series stations set in the WSG (station K2: $47^{\circ} \mathrm{N}, 160^{\circ} \mathrm{E}$ ) and subtropics (station $\mathrm{S} 1: 30^{\circ} \mathrm{N}, 145^{\circ} \mathrm{E}$ ). These two regions are characterized by different physical, chemical, and biological oceanography and are subjected to diverse allochthonous forcing, including seasonal monsoons, mesoscale eddies, and eolian inputs. This observational study, entitled "Study of change in ecosystem and material cycle caused by climate change and its feedback in the western North Pacific", commonly named "K2S1 Project", was initiated in 2010. Seasonal scientific cruises of the R/V Mirai were conducted between 2010 and 2013. Time-series observations were carried out using mooring systems that included sediment traps, water samplers, and primary productivity profilers. Besides these oceanographic observations, satellite data analyses and numerical simulations were used to elucidate inter-annual and decadal variability in meteorological and oceanographic conditions and to clarify the mechanisms associated with the cycling of materials at these stations.

The multidisciplinary research carried out as a part of the K2S1 Project involved the collaboration of scientists from various fields. That collaboration produced a great 
synergy of effects. One of the scientific highlights was the discovery that primary productivity at the oligotrophic station S1 was comparable to that at the eutrophic station K2. The multidisciplinary investigations identified the likely "missing nutrient source" at station S1 as a combination of regeneration, mesoscale eddy-driven upwelling, meteorological events, and eolian inputs in addition to winter vertical mixing. This volume provides essential information about the Western Pacific ecosystem, physics, and biogeochemistry based on shipboard observations, analysis of satellite data, and numerical simulations. More scientific products will be presented in the near future. Preliminary cruise reports and metadata from the K2S1 Project are available from the Japan Agency for Marine-Earth Science and Technology (JAMSTEC) "DARWIN" database (http://www.godac.jamstec.go.jp/darwin/datasearch/?full= \&lat $\mathrm{N}=$ \&lat $\mathrm{S}=$ \&lon $\mathrm{W}=\&$ lon $\mathrm{E}=\& \mathrm{sc}=0 \& \ln =1 \&$ word $=$ MIRAI\&search $=$ Search\&langUrlStr=e\#sc-result-box). In addition, essential data such as concentrations of oxygen, nutrients, chlorophyll, and fluxes of settling particles are available from the "K2S1 Database" (http://ebcrpa.jamstec. go.jp/k2s1/en/).

The K2S1 Project was initiated by Dr. Toshiro Saino, who was a professor emeritus of Nagoya University and former program director of the Environmental Biogeochemical Cycle Research Program, Research Institute for Global Change, JAMSTEC. Dr. Saino passed away in April 2014. Without his knowledge and experience derived from his involvement with and contributions to international scientific programs such as JGOFS and PICES, the K2S1
Project would not have been successful. Thanks to his passion and negotiating skills, seasonal scientific cruises and interdisciplinary studies with scientists from inside and outside of JAMSTEC became a reality. May his soul rest in peace.

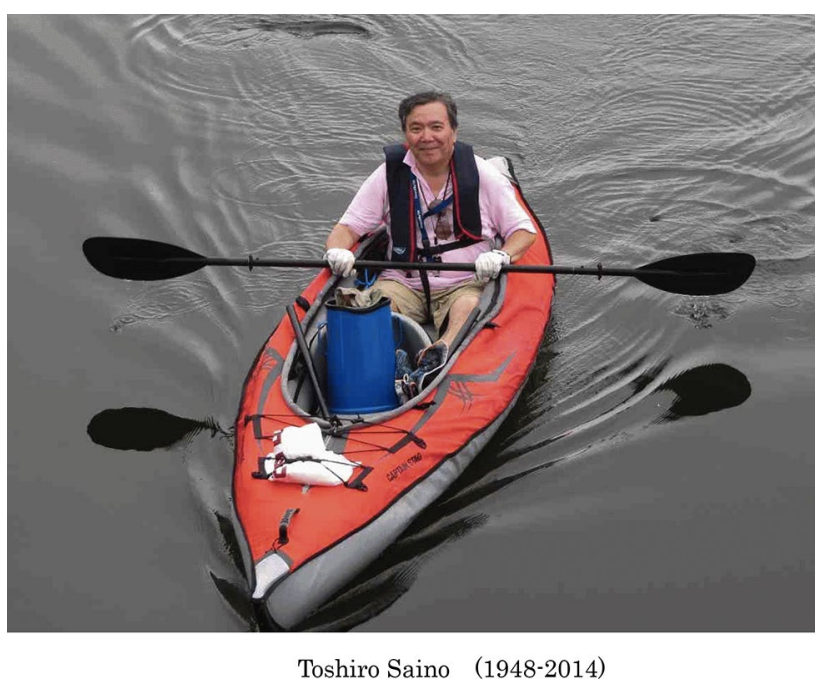

